\title{
PREPARATIONS FOR REMEDIATION OF A FORMER SURFACE MINE - A TECHNICAL RECLAMATION AREA
}

\author{
PETR ČERNOCH ${ }^{a, *}$, JiŘí KošŤÁL ${ }^{b, c}$ \\ ${ }^{a}$ ČEZ Energetické produkty, s.r.o., Komenského 534, 25301 Hostivice, Czech Republic \\ ${ }^{b}$ INSET, s.r.o., Division of Energetics, Lucemburská 7, 13000 Prague, Czech Republic \\ ${ }^{c}$ Czech Technical University in Prague, Faculty of Civil Engineering, Department of Geotechnics, Thákurova \%, \\ 16629 Prague, Czech Republic \\ * corresponding author: cernoch.petr@inset.com
}

\begin{abstract}
The reclamation area for secondary float energy by-products is located on a spoil heap, $45 \mathrm{~m}$ thick and 30 years old, and consists mostly of clay stone with high plasticity. When depositing a first $18 \mathrm{~m}$ high stack, it was necessary to verify stability and to analyse deformations during the reclaiming operation. Stability and deformation depend on the shallow groundwater level. Therefore, it was necessary to propose a technical solution for drainage of the structure concerned. This can be divided into two parts: drainage of surface water and drainage of the shallow underground water. It means a complex solution for the entire construction that would not be possible without long-term monitoring of the construction and field mapping. Completion of the proposed facilities will increase the stability of the reclamation area and it will then be possible to continue with remediation of the former surface mine.
\end{abstract}

KEYWORDS: Remediation, reclamation, stability, monitoring, drainage.

\section{INTRODUCTION}

Brown coal mining entails a number of negative aspects, risks and difficulties that geotechnical study has to manage. One of them is the issue of addressing the impact on the environment after mining activities have ceased, and then restoring the sites where the mining activities were pursued. These aims are pursued by a technical reclamation and an area restoration project that is primarily directed at refilling low parts of the terrain that are the result of mining work. Subsequent revitalization of the landscape in a way that gives careful consideration to the surrounding environment is a comprehensive and long-term process. For this, as a matter of preference for restoration purposes, the method used involves depositing soil and materials that qualify as certified energy by-products [1] taken from adjacent coal-fired power plants.

In any technical reclamation by depositing energy by-products, potential geotechnical risks arise. In particular, among these are a possible rise in groundwater levels as a result of the additional load on the subsoil caused by the weight of the structures and getting to appropriate design solutions for the drainage of surface water, rainwater and shallow underground water from the repository area. Another phenomenon is the stability and deformation-related characteristics of the material that is deposited [2].

\section{The Structure Concerned And THe Working OBJectives}

\subsection{The Area of Interest AND its HISTORY}

The structure presented as identifiable with the technical reclamation area is located in the south-eastern part of an extended zone of surface mines and constitutes the refilling phase of a large-scale reclamation scheme to restore areas where there were formerly mining operations. The first written mention of mining activities in the wider area of the locality concerned date back to the second half of the 18th century when a brown coal seam was discovered here. In the early $1860 \mathrm{~s}$, there were already 36 mines in operation, with the first surface mine working a seam up to $8 \mathrm{~m}$ thick. The largest open pit mine began to be mined in 1917 and gradually went on to supply coal to nearby power plants. The bottom of the mine practically corresponded to the bottom of the seam; only the safety pillar of fixed reserves remained free of actual coal mining. The area of the depleted mine where the technical reclamation area structure is located was gradually filled with dump soil and overburden materials from adjacent smaller surface mines [3].

\subsection{Brief Description of the Structure AND NATURAl CONDitions}

The technical reclamation area is used in order to deposit energy by-products, specifically power plant fly ash mixtures, energy gypsum and other deposit materials. The depositing activities started in 1996 . The materials are deposited with a belt stacker (Figure 1) 
- a PVZ2500 crawler wagon with a boom length of up to $45 \mathrm{~m}$ and a total specified weight of 350 tons. The tripper car (weight 63 tons) supplying the stacker with material from the conveyor belt and the cable drum car (69 tons) that supplies power are essential parts of the material stacking technology. Subsequently, the material is shaped and compacted by a bulldozer.

The deposit material is prepared in the mixing centre of a nearby coal power plant. From a geomechanical point of view, the deposit material is a finegrained mixture consisting of $50-70 \%$ dust fraction and $35-45 \%$ sand fraction. The remainder of the grain size curve consists of a minor share of clay particles $(<0.002 \mathrm{~mm})$.

The area of interest is situated at the western edge of the North Bohemian Brown Coal Basin, specifically in the area of the Střezov ridge. The whole formation is broken by a number of minor transverse faults with Tertiary volcanic outcrops. The northern and eastern edge of the area is built of basin sediments, while volcanic rocks prevail at the western and southern edges. The north-western edge of the technical reclamation area is bordered by rocks of crystalline complex, which are exposed in the wider zone and form the subsoil of the basin sediments in the former mine area and its surroundings. Around the technical reclamation area, only the overlying strata are developed in lowest thicknesses of up to $15 \mathrm{~m}$, and are only present in the northern and eastern parts of the zone. The coal seam formation is found in most parts of the area of interest almost in practice at the level of the original or present surface of the terrain and alongside coal seams, and it contains xylites, oxyhumolites, grey-brown clay stones and powdery clay stones with a fluctuating content of coal admixture and coal components. In the subsoil there are clays of green shades with a high content of tuffitic material, which in places shift to tuffites and volcanic breccias. Their thickness is very variable (from $50 \mathrm{~m}$ to the lower hundreds of metres), depending on the morphology of the crystalline bedrock.

As in many similar cases, the technical reclamation area structure is here also located on the spoil heap. The immediate subsoil of the deposit body is the surface of an outer dump of overburden materials, consisting of clay soils with high plasticity, which is more than 30 years old and up to $45 \mathrm{~m}$ thick. Given the length of time the spoil heap has been exposed to climatic conditions, water infiltration and self-weight, its surface can be considered effectively consolidated. The northern part of the structure concerned already interferes with a part of the inner spoil heap.

The hydrogeological conditions in the wider area concerned have changed several times in recent history. Initially this was as a result of mining in the open pit mine and the consequent creation of the outer dump, and then later through the actual depositing of energy by-products. Because of the impermeable nature of the dump soils, they cannot be expected to have any presence in terms of a significant groundwater horizon; the groundwater level more or less copies the outer surface of the dump, except in the southern part of the structure. In the early stages of the depositing, the groundwater level in the dump ranged, depending on the terrain morphology, from $282 \mathrm{~m}$ above sea level (in the western part) to $315 \mathrm{~m}$ (in the eastern part). Under these circumstances, water flowed in a northerly direction towards the mine, and also southwards, to the local reservoir, which forms the drainage base of a wider area with a free water level at about $270 \mathrm{~m}$ above sea level. Deeper groundwater circulation is tied to coarse-grained sediments - Miocene sedimentary sands mixed with clay elements. In the southern and north-eastern front zone of the structure, there are permanently waterlogged places which are relatively large in area.

The region concerned is characterized by low rainfall and relatively high air temperatures. Western winds prevail; the climate is warm, with a cooler spring and warm autumn. Winter is mild to moderately warm. The original slope of the terrain on the site of the technical reclamation area was towards the south. After backfilling with material from the outer dump, the general slope of the surface changed to that of falling slightly towards the north. The present slope and terrain morphology are the result of how the depositing of energy by-products progressed [4].

The entire structure has been subject to long-term monitoring both by hydrogeological probes (observation boreholes) and through geotechnical inspection monitoring elements (inclinometric probes, pore pressure gauges installed in boreholes, and geodetic points).

\subsection{OBJECTIVE OF THE WORK}

Over the course of depositing the first layer of the deposit material, about $18 \mathrm{~m}$ thick in the technical reclamation area, the need emerged to verify the stability of the emergent deposit body of energy by-products and to analyse the expected deformations in connection with the operation of stacking machinery at the minimum permissible distance of the stacker from the edge of the slope crest.

The aim of the stability and deformation-related calculations was to determine the distance at which the earthwork carrying the weight of the stacking machinery has adequate long-term stability. Furthermore, partial stability calculations were carried out - primarily to determine the preliminary stability of the northern slopes of the structure near the service road of the surface mine. Another area of focus was the slopes delimiting the borrow pit in the east of the technical reclamation area (for short-term stability at the time of excavation). Finally, there was also a focus on the southern slopes of the area of interest, which had the least favourable morphology and geological conditions - here the long-term and permanent stability of the deposit body and the southern front zone was assessed. 


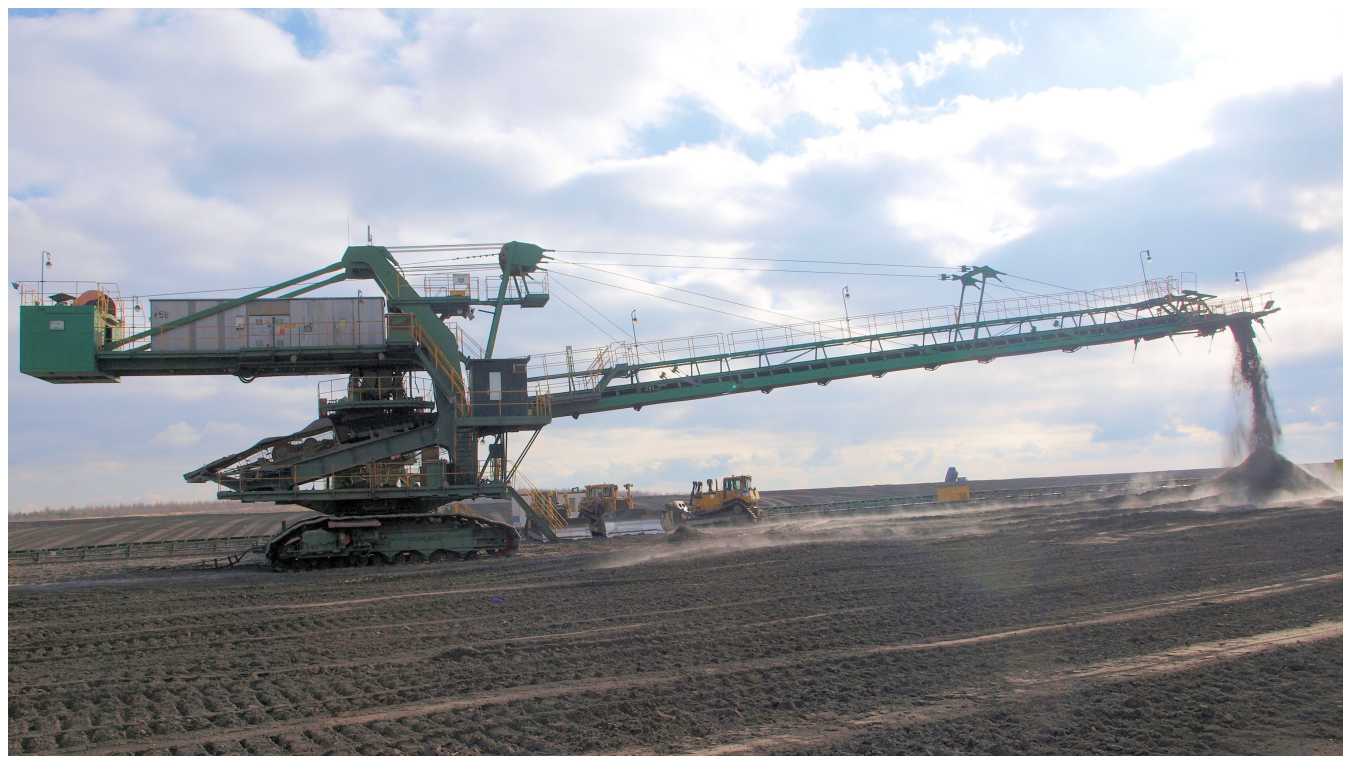

FiguRE 1. Stacking the deposit material in the technical reclamation area using a belt stacker.

The stability and deformations of the body of energy by-products that was examined are significantly dependent on the shallow groundwater level. Therefore, apart from the aforementioned calculations, it was also necessary to propose a technical solution for the drainage of the structure concerned. This also doubled in function as reference documents for updating the project for the technical reclamation of the area of interest. On the basis of the results of the field mapping and geodetic surveying of important points, a proposal for the drainage system of the structure was subsequently conceived. The drainage solution can be split into two logical parts: surface water and rainwater drainage and runoff, and then also drainage of shallow underground water.

This was therefore a complex geotechnical solution, involving long-term monitoring of the area of interest, and including extensive archival research, all used as a basis for the stability and deformation-related calculations. Subsequently, on the basis of their results and the field mapping, a comprehensive draft design of the structure and its shape, including drainage, was conceived.

\section{ImPlementation OF THE WORK and Operational Results}

\subsection{Stability and Deformation Calculation}

The GEO 5 and PLAXIS software were used to calculate stress-strain behaviour and slope stability. The first of these uses the limit force equilibrium method to perform the calculation. The Bishop's shearing surface optimization method was used to determine the critical least favourable shearing surface with the lowest local degree of stability. The optimisation was worked out by gradually changing the positions of individual points on the surface and determining which change in a given point's position resulted in the lowest degree of stability. The numerical model specified in the PLAXIS software works on the basis of the finite element method (FEM), and determines the degree of stability by automatic simultaneous reduction of the cohesion values and the tangent of the internal friction angle ( $\varphi$ and $c$ reduction).

The calculations were divided into steps corresponding to the expected work procedures. For each phase of the construction and load effect, a calculation focusing on the deformations caused by the static load was also performed. As an additional part of the calculation, a state was also modelled with an additional load from the stacker, taking into account the dynamic effects or simultaneous operation of pertinent machinery (the tripper car, cable drum car, middle parts, and material being transported) - thus procedural safety. The contact area of the caterpillar bands was modelled using two contact rectangles. The characteristic contact stress was calculated from the total weight of the stacker and the total area of the caterpillar bands, i.e. from the relation:

$$
F=\frac{m_{\text {tot }} g}{S_{\text {hous }}}=\frac{500000 \times 10}{2.4 \times 8.6 \times 2}=121 \mathrm{kN} / \mathrm{m}^{2},
$$

where $F$ is the characteristic contact stress, $m_{\text {tot }}$ the total weight of the stacker and $S_{\text {hous }}$ the area of the caterpillar bands.

The terrain morphology data that was used in the calculation model was based on the geodetically measured input. The boundaries between geological quasi-homogeneous units (geo-types) and the line of the groundwater level were processed on the basis of archival research and the results of long-term monitoring. In total, four computational profiles were created, three of which dealt with problematic areas of the structure (see Chapter 2.3), while one section was used to determine the usability of the stacker for future levels of the deposit body (see above). 
The groundwater level was entered as a polygon, under which the mass unit weight of saturated soil and upward hydrostatic pressure was considered by the software in the calculation, and above it the entered mass unit weight value. The pore water pressure at a given point was calculated as the hydrostatic pressure, with the line of the groundwater level being taken into account. In dealing with the effect of the load on a level from the stacker, the groundwater level was assumed to be sufficiently deep below the bottom surface of the deposit body that in consequence its effect was negligible. In the remaining profiles, however, the groundwater level played a significant role. It was not possible to enter the course of infiltrated water, leachate water and drainage water (discontinuous and varying groundwater levels) into the calculation. However, thanks to the results of the monitoring of the structure that was implemented, the places where there was permanent surface waterlogging in the front zone of the technical reclamation area were sufficiently mapped, which made it possible to include them in the numerical modelling.

The results of the limit force equilibrium method showed that approaching the edge of the slope to a distance of $5 \mathrm{~m}$ with the stacker causes a deformation stress state in the earthwork with a degree of safety $F_{\mathrm{S}}=1.69$ and a maximum total deformation of the deposit body of $0.25 \mathrm{~m}$. In numerical verification using the finite element method, the total degree of stability was determined at $F_{\mathrm{S}}=1.63$. The shortest possible distance the stacker can travel to the edge of the earthwork, determined in this way, does not pose a technological restriction on operations, which is of key importance for further depositing processes. The additional load from the stacker caused deformations with their direction and size evident from the shift vectors (Figure 2). The model showed a significant predominance of vertical over horizontal deformations, providing the stacking is within acceptable limits. The calculations performed did not indicate tensile cracking and only then to a negligible extent on the surface of the deposited material [5].

The stability calculation showed compliance with the requirement of short-term stability for profiles running through the northern slopes of the technical reclamation area and in the area near the borrow pit in the eastern part of the area of interest $\left(F_{\mathrm{S}}=2.30\right.$ and $F_{\mathrm{S}}=1.47$ respectively). For the southern front zone of the structure, the resulting degree of stability was determined at $F_{\mathrm{S}}=1.05$. In conclusion, the resulting slope stability only met the requirements to a certain extent and did not meet the requirement of long-term stability. The results obtained were affected both by the shear parameters of the soils (which depend, inter alia, on the degree of consolidation, which in turn is influenced by the age and thickness of the deposit layers) and by the line of the groundwater level. It was therefore recommended to draft construction and technical measures that minimize unwanted soil saturation with rainwater in the southern front zone of the structure and that at the same time facilitate the runoff of shallow underground water from the technical reclamation area and from the affected area of permanent waterlogging in the southern front zone of the structure concerned.

Another output from the calculations that were performed was the conclusion that in the further stacking of the deposit material, any significant rise in the groundwater level in the subsoil should be avoided. It was therefore recommended to increase the frequency of measurements of groundwater levels in the monitoring wells and to install additional observation probes in the risk area for the shallow groundwater level horizon - observation piezometers and boreholes [6].

\subsection{EARTHWORKS}

From the above, the necessity arose of detailed mapping of the technical reclamation area with a focus on the current state of the surface waterlogging and drainage of the structure. The reconnaissance of the area of interest included a precise geodetic survey of significant hydrological elements and phenomena. During the fieldwork, concrete troughs were found to be clogged (with a layer of mud up to $40 \mathrm{~cm}$ thick) in many places, or entirely missing. In some places, undesirable aquifers thus formed (Figure 3). Surface water and rainwater from the mine service road should be channelled through an open ditch to the existing accumulation sump in the eastern part of the area of interest; however, the ditch is blinded and hence not functional.

\section{Draft Technical Solution and RECOMMENDATIONS}

On the basis of the work carried out, a comprehensive solution of the technical reclamation area was proposed. This included in particular the draft design of the drainage method split into two main parts: a solution to surface water and rainwater runoff, and a solution to the drainage of shallow groundwater.

\subsection{Drainage of Surface Water and RAINWATER}

In designing the method for the drainage of surface water and rainwater, it was proposed to use the existing concrete trough combined with new piping. The existing troughs will need to be cleaned and those that are broken restored. Subsequently, a DN 500 pipe of flexible material (PVC) that allows bending will be laid in the concrete trough. This piping will provide drainage of surface water even after the backfilling of the trough. It will be necessary to connect the piping at the southern portal through a connection under the service road (which includes lifting the blinding) and terminate it at the point of the drainage inflow to the sump area - the pipe outlet. The entire section concerned has a length of $523 \mathrm{~m}$, and from $401 \mathrm{~m}$ to $523 \mathrm{~m}$ the concrete troughs are actually missing. 


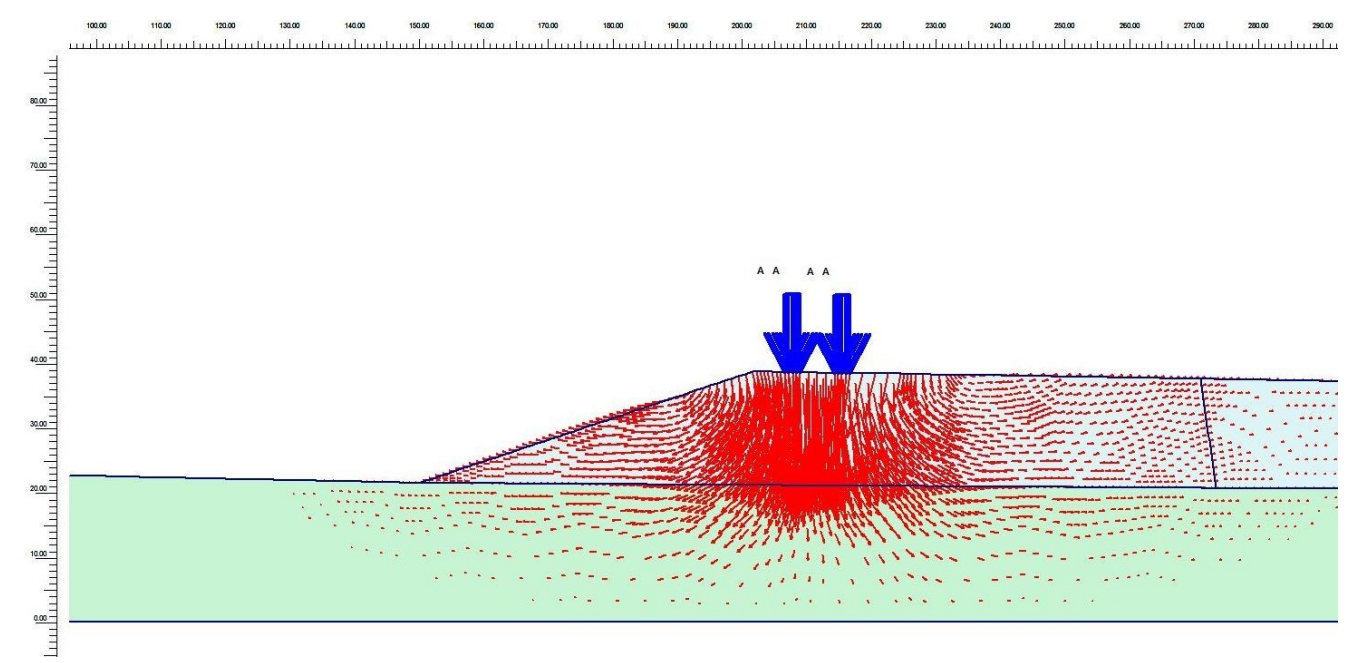

Figure 2. Total deformation caused by additional load from the belt stacker.

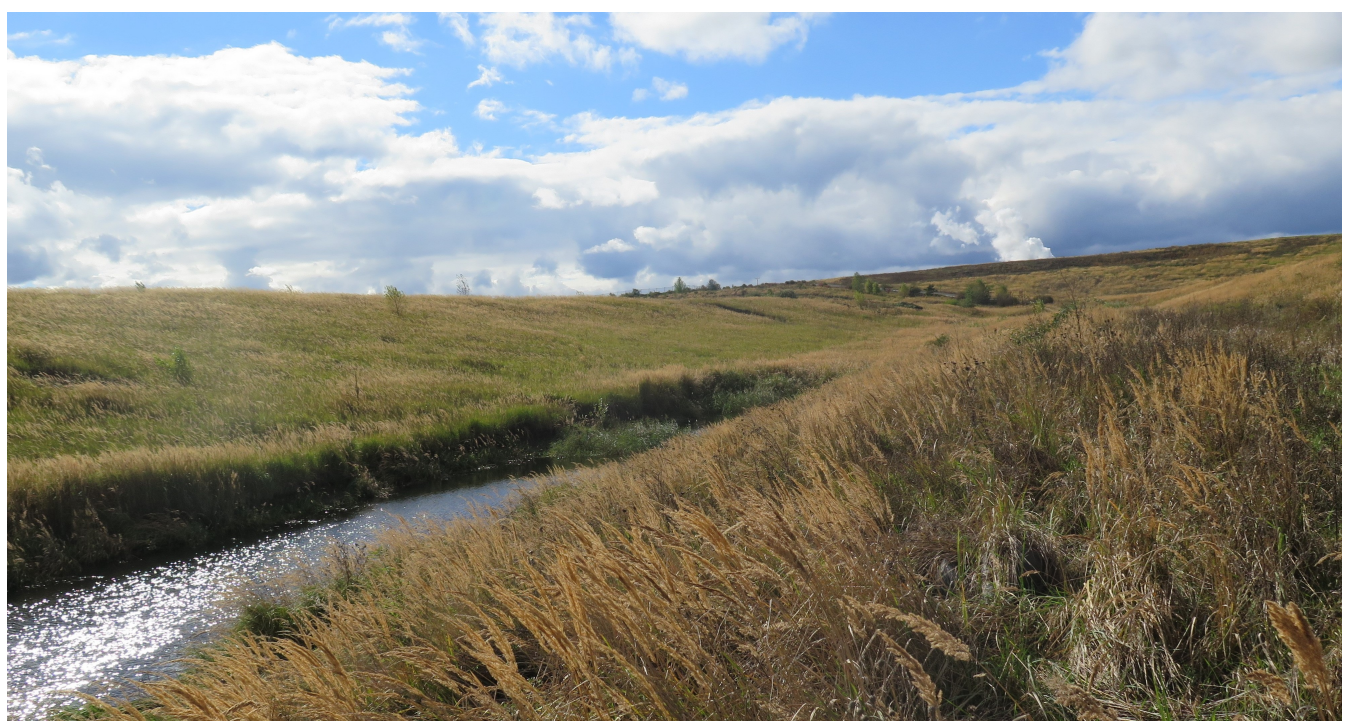

FIGURE 3. Waterlogging as a result of clogging or absence of surface drainage.

There we recommend laying new concrete troughs while maintaining the proposed slope.

\subsection{Drainage of Shallow Underground WATER}

The drainage of shallow underground water involves the implementation of a ground trench $(1.0 \mathrm{~m}$ in depth with a minimum bottom width of $1.0 \mathrm{~m})$, lined with a separation geotextile and supplemented with a DN 800 perforated drainage pipe of flexible material (PVC), covered with quarry stone (grain size $>32 \mathrm{~mm}$ ) and a separation geotextile. The bottom of the excavation pit, consisting of impermeable dump soil, will be compacted. Should any places with coarse-grained fractions be found, these will be replaced with the surrounding fine-grained dump soil and subsequently compacted. The drainage of shallow groundwater will be terminated at the point of the drainage inflow from the area of the front dump of the surface mine. From there, the route will continue on a downward slope with troughs all the way to the sump. The drainage pipe will be $377 \mathrm{~m}$ long, the entire section concerned being $499 \mathrm{~m}$ in length.

Water surfaces cause waterlogging of the bottom of the deposit body; thus it was recommended to dispose of this by pumping and backfilling to a sufficient level that a renewed water retention is prevented. This measure, along with the implementation of the drainage, will significantly increase the stability of the slopes concerned. Their stability should be verified before continuing with the depositing of another level [7].

\section{Conclusions}

A comprehensive series of works was carried out for the project of the technical reclamation of the structure concerned, all aimed at restoring the site of former mining activities by refilling with a certified product of a coal-fired power plant; these included the archival research, stability and deformation numerical calculations using data from long-term monitoring of the structure, and field mapping. The result of the works 
that were carried out was presentation of a draft technical solution for the drainage of the area of interest, intended to increase the stability of the structure under monitoring and enable its continued existence. In further stacking, any significant rise in the groundwater level in the subsoil should be avoided, and so a higher frequency of groundwater level measurements in the monitoring probes, as well as some additional probes, was recommended.

\section{REFERENCES}

[1] P. Černoch, J. Koštál. Příprava sanace bývalého povrchového dolu/odkaliště. In Proceedings of conference Geotechnika 2018, Vysoké Tatry. Orgware, 2018.
[2] P. Černoch, J. Koštál. Geotechnical risks of foundation of warehouses built on brownfields. Repair and Maintenance Strategies of Geotechnical Structures 2(2-3):981-986, 2018.

[3] P. Černoch, J. Koštál. GT práce na rozširření úložného prostoru. INSET s.r. o., 2013.

[4] P. Černoch. Hydrogeologické a hydrochemické sledování. Výsledky za rok 2017, INSET s. r. o.

[5] J. Janků. Stabilitní výpočet provozního svahu z deponátu úložiště. INSET s.r. o., 2016.

[6] P. Černoch, J. Janků. PTR. přepočet stability. ČEZ EP, s. r. o., 2017.

[7] P. Černoch, P. Straková. Návrh odvodnění předvýsypky PTR. INSET s.r.o., 2016. 